\title{
Carry Trades and Currency Crashes
}

Markus K. Brunnermeier, Princeton University, NBER, and CEPR

Stefan Nagel, Stanford University and NBER

Lasse H. Pedersen, New York University, NBER, and CEPR

\section{Introduction}

This paper studies crash risk of currencies for funding-constrained speculators in an attempt to shed new light on the major currency puzzles. Our starting point is the currency carry trade, which consists of selling low interest rate currencies- "funding currencies"-and investing in high interest rate currencies- "investment currencies." While the uncovered interest rate parity (UIP) hypothesizes that the carry gain due to the interest rate differential is offset by a commensurate depreciation of the investment currency, empirically the reverse holds, namely, the investment currency appreciates a little on average, albeit with a low predictive $R^{2}$ (see, e.g., Fama 1984). This violation of the UIP—often referred to as the "forward premium puzzle" - is precisely what makes the carry trade profitable on average. Another puzzling feature of currencies is that dramatic exchange rate movements occasionally happen without fundamental news announcements, for example, the large depreciation of the U.S. dollar against the Japanese yen on October 7 and 8, 1998, depicted in figure $1 .^{1}$ This reflects the broader phenomenon that many abrupt asset price movements cannot be attributed to a fundamental news events, as documented by Cutler and Summers (1989) and Fair (2002).

We conjecture that sudden exchange rate moves unrelated to news can be due to the unwinding of carry trades when speculators near funding constraints. This idea is consistent with our findings that (i) investment currencies are subject to crash risk, that is, positive interest rate differentials are associated with negative conditional skewness of exchange rate movements; (ii) the carry, that is, interest rate differential, is associated with positive speculator net positions in investment currencies; (iii) speculators' positions increase crash risk; (iv) carry trade 


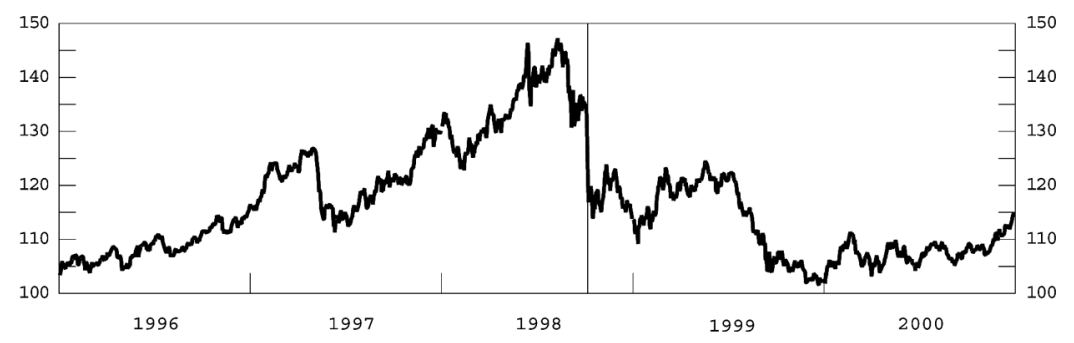

Fig. 1. U.S. dollar/Japanese yen exchange rate from 1996 to 2000

losses increase the price of crash risk but lower speculator positions and the probability of a crash; (v) an increase in global risk or risk aversion as measured by the VIX equity-option implied volatility index coincides with reductions in speculator carry positions (unwind) and carry trade losses; (vi) a higher level of VIX predicts higher returns for investment currencies and lower returns for funding currencies, and controlling for VIX reduces the predictive coefficient for interest rate differentials, thus helping resolve the UIP puzzle; (vii) currencies with similar levels of interest rate comove with each other, controlling for other effects. (viii) More generally, the crash risk we document in this paper may discourage speculators from taking on large enough positions to enforce UIP. Crash risk may thus help explain the empirically well-documented violation of the UIP.

Our findings share several features of the "liquidity spirals" that arise in the model of Brunnermeier and Pedersen (2009). They show theoretically that securities that speculators invest in have a positive average return and a negative skewness. The positive return is a premium for providing liquidity, and the negative skewness arises from an asymmetric response to fundamental shocks: shocks that lead to speculator losses are amplified when speculators hit funding constraints and unwind their positions, further depressing prices, increasing the funding problems, volatility, and margins, and so on. Conversely, shocks that lead to speculator gains are not amplified. Further, Brunnermeier and Pedersen (2009) show that securities where speculators have long positions will move together, as will securities that they short.

In the currency setting, we can envision a country suddenly increasing its interest rate and thereby attracting foreign capital-possibly worsening the current account. ${ }^{2}$ In a frictionless and risk-neutral economy, this should lead to an immediate appreciation of the currencyassociated with an inflow of capital-and a future depreciation of the exchange rate such that UIP holds. In the presence of liquidity constraints, 
however, capital only arrives slowly such that the exchange rate only appreciates gradually, occasionally disrupted by sudden depreciations as speculative capital is withdrawn. Mitchell, Pedersen, and Pulvino (2007) document the effect of slow-moving capital in other markets.

In contrast, a crash after a "currency bubble," which can emerge when each investor holds on to his carry trade position too long since he does not know when others unwind their position, can be price correcting (Abreu and Brunnermeier 2003). Plantin and Shin (2007) show in a dynamic global games framework that carry trades can be destabilizing when strategic complementarities arise, which is the case if (i) speculators' trades occur sequentially in random order and (ii) as in Brunnermeier and Pedersen (2009), trading requires capital and margins requirements become more stringent when liquidity is tight. Our empirical findings suggest an initial underreaction due to slow-moving capital subject to liquidity risk but are also consistent with a long-run overreaction.

Our empirical study uses time-series data on the exchange rates of eight major currencies relative to the U.S. dollar. For each of these eight currencies, we calculate realized skewness from daily data within (overlapping) quarterly time periods. We show in the cross section and in the time series that high interest rate differentials predict negative skewness, that is, carry trade returns have crash risk. Our finding is consistent with the saying among traders that "exchange rates go up by the stairs and down by the elevator." We note that this saying must be understood conditionally: currencies do not have unconditional skewnessthat is, the skewness of a randomly chosen currency pair is zero-because country A's positive skewness is country B's negative skewness. Hence, our finding is that the trader saying holds for investment currencies, while the reverse holds for funding currencies. Further, we find that high interest rate differentials predict positive speculator positions, consistent with speculators being long the carry trade on average. The top panel in figure 2 clearly shows a negative relationship between average currency skewness and the average interest rate differential. We see that the countries line up very closely around the downward sloping line, with an $R^{2}$ of $81 \%$. For example, skewness is positive and highest for Japanese yen ( $a$ "funding currency"), which also has the most negative interest rate differential. At the other end of the skewness spectrum, one finds the the two major "investment currencies" Australian and New Zealand dollar, which have the second-highest interest rate differentials.

Next, we study the risk premium associated with crash risk, that is, the "price" of crash risk. In particular, we consider the so-called risk reversal, which is the implied volatility of an out-of-the-money call 

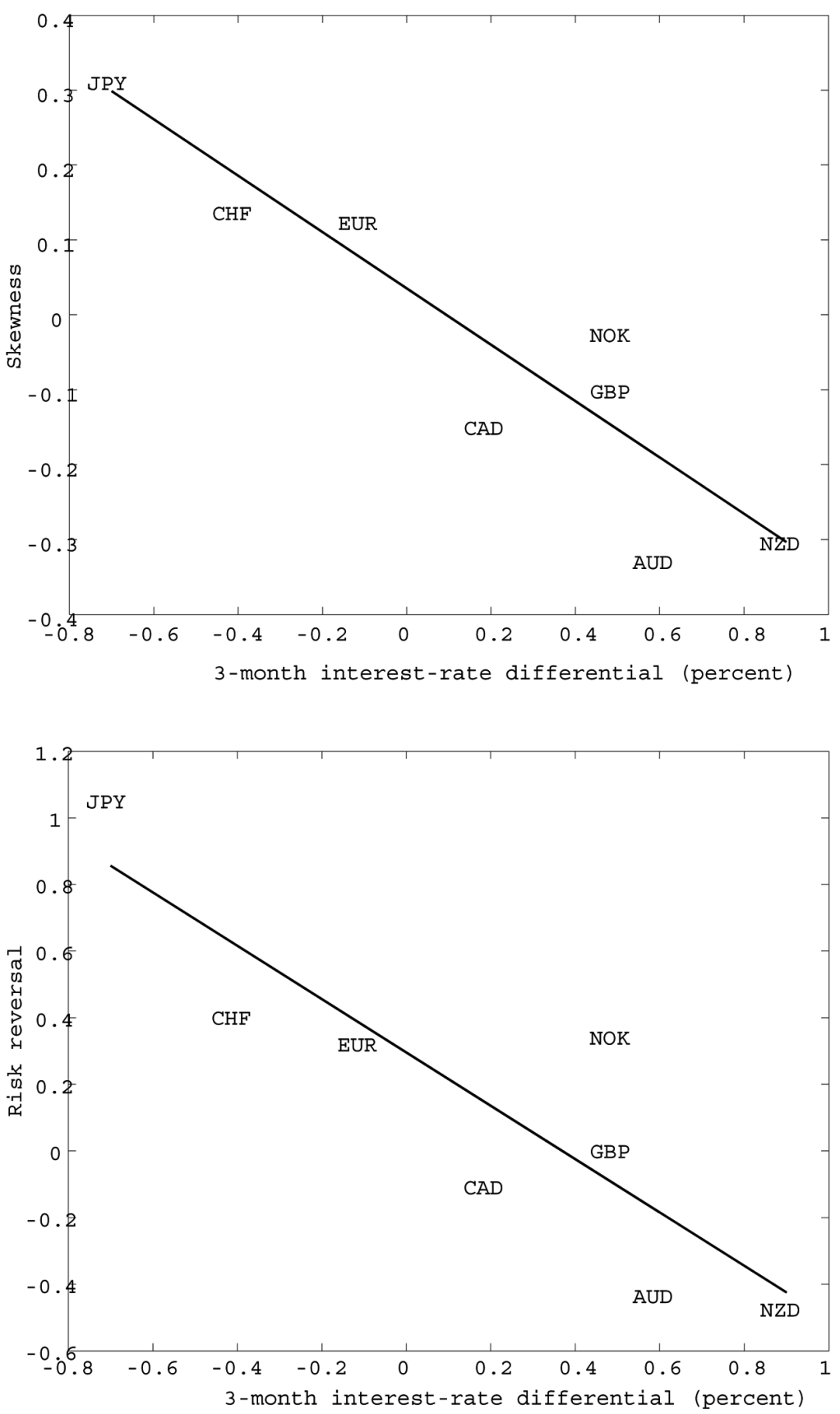

Fig. 2. Cross-section of empirical skewness (top panel) and of risk reversal (bottom panel), reflecting implied (risk-neutral) skewness, for different quarterly interest rate differentials $i^{*}-i$. 
option minus the implied volatility of an equally out-of-the-money put. If the exchange rate is symmetrically distributed under the risk-neutral measure, then the risk reversal is zero since the implied volatilities are the same. This means that the cost of a call can be offset by shorting the put. On the other hand, if the risk-neutral distribution of the exchange rate is negatively (positively) skewed, the price of the risk reversal is negative (positive). Hence, the risk reversal measures the combined effects of expected skewness and a skewness risk premium. Said differently, it measures the cost of buying protection on a currency position to limit the possible gains and losses.

In the cross section, the average implied skewness from risk reversals is also negatively related to the average rate differential (bottom panel of fig. 2), suggesting a close cross-sectional relationship between our physical skewness measure and the risk-neutral implied skewness. The time-series relationship between actual skewness and price of a risk reversal contract is more surprising: a higher risk reversal predicts a lower future skewness, controlling for the interest rate differential. This finding is related to our finding that carry trade losses lead to lower speculator positions, a higher risk reversal, and a lower future skewness, though we must acknowledge the possible peso problem in estimation. ${ }^{3}$ Hence, after a crash, speculators are willing to pay more for insurance, the price of insurance increases, and the future crash risk goes down, perhaps because of the smaller speculator positions. This has parallels to the market for catastrophe insurance as documented by Froot and O'Connell (1999) and Froot (2001).

Funding constraints are likely to be particularly important during financial dislocations when global risk or risk aversion increases, leading to possible redemptions of capital by speculators, losses, increased volatility, and increased margins. To measure this, we consider the implied volatility of the S\&P 500, called the VIX. Note that the VIX, which is traded at the Chicago Board Options Exchange (CBOE), is not mechanically linked to exchange rates since it is derived from equity options. We show that during weeks in which the VIX increases, the carry trade tends to incur losses. We also find that risk-reversal prices and carry trade activity (both contemporaneous and predicted future activity) decline during these times. The decrease in the price of risk reversals could be due to an increase in the price of insurance against a crash risk, or it could simply reflect an objective increase in the probability of a crash. As another proxy for funding liquidity, we also examine the effect of the TED spread, the difference between the London Interbank 
Offered Rate (LIBOR) interbank market interest rate and the risk-free T-Bill rate. An increase in the TED spread has effects similar to an increase in the VIX although with less statistical power.

Further, we find that high levels of the TED and the VIX predict higher future returns to the carry trade, that is, relatively higher returns for high interest currencies and low returns to low interest currencies. Importantly, controlling for this effect reduces the predictability of interest rates, that is, this helps to explain the UIP violation. Overall, these findings are consistent with a model in which higher implied volatility or TED spread leads to tighter funding liquidity, forcing a reduction in carry trade positions, thus making the underreaction stronger and returns higher going forward.

Finally, we document that currencies with similar interest rate comove, controlling for certain fundamentals and country-pair fixed effects. This could be due to common changes in the size of the carry trade that lead to common movements in investment currencies, and common opposite movements in funding currencies.

The structure of the paper is the following. Section II provides a brief summary of related papers. Section III describes the data sources and provides summary statistics. Our main results are presented in Section IV. Section V concludes.

\section{Related Literature}

There is an extensive literature in macroeconomics and finance on the forward premium puzzle, which focuses implicitly on the mean return of the carry trade. Froot and Thaler (1990), Lewis (1995), and Engel (1996) are nice survey articles. The forward premium puzzle is also related to Meese and Rogoff's (1983) finding that exchange rates follow a "near random walk" allowing investors to take advantage of the interest differential without suffering an exchange rate depreciation. It is only a near random walk since high-interest-bearing currencies even tend to appreciate (albeit with a low forecast $R^{2}$ ) and in the long run exchange rates tend to converge to their purchasing power parity levels.

More recently, Bacchetta and van Wincoop (2007) attribute the failure of UIP to infrequent revisions of investor portfolio decisions. Lustig and Verdelhan (2007) focus on the cross-sectional variation between the returns of high and low interest rate currencies and make the case that the returns on currencies with high interest rates have higher loading on 
consumption growth risk. Burnside (2007) argues, however, that their model leaves unexplained a highly significant excess zero-beta rate (i.e., intercept term), and Burnside et al. (2006) find that the return of the carry trade portfolio is uncorrelated to standard risk factors, attributing instead the forward premium to market frictions (bid-ask spreads, price pressure, and time-varying adverse selection in Burnside, Eichenbaum, and Rebelo [2007]). Jylhä, Lyytinen, and Suominen (2008) argue that inflation risk is higher in high interest rate currencies and show a positive relationship between carry trade returns and hedge fund indices.

Our analysis is among the first to examine empirically the skewness of exchange rate movements conditional on the interest rate differential, that is, on the crash risk of carry trade strategies. Farhi and Gabaix (2008) develop a model in which the forward premium arises because certain countries are more exposed to rare global fundamental disaster events. Their model is calibrated to also match skewness patterns obtained from FX (foreign exchange) option prices. Instead of focusing on exogenous extreme productivity shocks, we provide evidence consistent with a theory that currency crashes are often the result of endogenous unwinding of carry trade activity caused by liquidity spirals. Bhansali (2007) argues that carry trades are essentially short volatility and documents that optionbased carry trades yield excess returns. Jurek (2007) finds that the return to the carry over the period 1999-2007 with downside protection from put options of various moneyness is positive. Further, he finds that the more protection one buys on the carry trade, the smaller is the average return and Sharpe ratio. Ranaldo and Söderlind's (2007) finding that safe-haven currencies appreciate when stock market volatility increases can be related to our third set of findings that unwinding of carry trades is correlated with the volatility index, VIX.

Gagnon and Chaboud (2007) focus primarily on the U.S. dollar to Japanese yen exchange rate and link the crashes to balance sheet data of the official sector, the Japanese banking sector and households. Galati, Heath, and McGuire (2007) point to additional data sources and net bank flows between countries that are useful for capturing carry trade activity. Klitgaard and Weir (2004) make use of weekly net position data on futures traded on the CME-as we do-and document a contemporaneous (but not predictive) relationship between weekly changes in speculators' net positions and exchange rate moves. Finally, there are numerous papers that study crash risk and skewness in the stock market. Chen, Hong, and Stein (2001) seems to be closest to our study. 


\section{Data and Definitions}

We collect daily nominal exchange rates to the U.S. dollar (USD) and 3-month interbank interest rates from Datastream from 1986 to 2006 for eight major developed markets: Australia (AUD), Canada (CAD), Japan (JPY), New Zealand (NZD), Norway (NOK), Switzerland (CHF), Great Britain (GBP), and the euro area (EUR), as well as the eurodollar LIBOR. For the period before the introduction of the euro on January 1 , 1999, we splice the euro series together with the exchange rate of the German mark to the U.S. dollar, and we use German 3-month interbank rates in place of euro interbank rates. For most tests below we use a quarterly horizon to measure exchange rate changes, and hence 3 months is the appropriate horizon for interest rates to apply uncovered interest parity in straightforward fashion.

We denote the logarithm of the nominal exchange rate (units of foreign currency per dollar) by

$$
s_{t}=\log (\text { nominal exchange rate) } .
$$

The logarithm of the domestic U.S. interest rate at time $t$ is denoted by $i_{t}$ and the log foreign interest rate by $i_{t}^{*}$. We denote the return of an investment in the foreign currency investment financed by borrowing in the domestic currency by

$$
z_{t+1} \equiv\left(i_{t}^{*}-i_{t}\right)-\Delta s_{t+1}
$$

where $\Delta s_{t+1} \equiv s_{t+1}-s_{t}$ is the depreciation of the foreign currency. It is a measure of exchange rate return in excess of the prediction by uncovered interest parity since under UIP, $z_{t}$ should not be forecastable:

$$
E_{t}\left[z_{t+1}\right]=0 \text {. }
$$

Hence, one can think of $z$ as the abnormal return to a carry trade strategy where the foreign currency is the investment currency and the dollar is the funding currency. In most of our analysis, and in line with most of the literature on UIP, we look at interest rate differentials and currency excess returns expressed relative to the USD. Carry traders, however, do not necessarily take positions relative to the USD. For example, to exploit the high interest rates in AUD and the low interest rates in JPY in recent years, carry traders may have taken a long position in AUD, financed by borrowing in JPY (or the synthetic equivalent of this position with futures or OTC currency forwards). Our analysis nevertheless sheds light on the profitability of such a strategy. The AUD in recent years offered higher interest rates than USD, so our regressions predict an appreciation of the 
AUD relative to the USD. The JPY in recent years offered lower interest rates than USD, and hence our regressions predict a depreciation of the JPY relative to the USD. Taken together, then, our regressions predict a depreciation of the JPY relative to the AUD. Thus, while we do not directly form the carry trade strategies that investors might engage in, our regressions are nevertheless informative about the conditional expected payoffs of these strategies.

Much of our analysis focuses on the skewness of exchange rate movements. To that end, we measure the skewness of daily exchange rate changes $(-\Delta s)$ within each quarter $t$, denoted Skewness $t$.

As a proxy for carry trade activity, we use the futures position data from the Commodity Futures Trading Commission (CFTC). Our variable Futures $t_{t}$ is the net (long minus short) futures position of noncommercial traders in the foreign currency, expressed as a fraction of total open interest of all traders. Noncommercial traders are those that are classified as using futures not for hedging purposes by the CFTC. This basically means that they are investors that use futures for speculative purposes. We have data from 1986 for five countries (CAD, JPY, CHF, GBP, EUR), and, in our quarterly analysis, we use the last available CFTC positions report in each quarter. A positive futures position is economically equivalent to a currency trade in which the foreign currency is the investment currency and the dollar is the funding currency, and, indeed, few speculators implement the carry trade by actually borrowing and trading in the spot currency market. We note, however, that the position data are not perfect because of the imperfect classification of commercial and noncommercial traders and, more importantly, because much of the liquidity in the currency market is in the over-the-counter forward market. Nevertheless, our data are the best publicly available data, and they give a sense of the direction of trade for speculators.

We use data on foreign exchange options to measure the cost of insuring against crash risk or, said differently, the risk-neutral skewness. Specifically, we obtain data from JPMorgan Chase on quotes of $25 \Delta 1$-month risk reversals. ${ }^{5} \mathrm{~A}$ risk reversal is the difference between the implied volatility of an out-of-the-money FX call option and the implied volatility of an out-of-the-money FX put option. This is a measure of the cost of a long position in a call combined with a short position in a put, that is, the cost of buying insurance against foreign currency appreciation, financed by providing insurance against foreign currency depreciation. ${ }^{6}$ If the underlying distribution of exchange rate movements is symmetric, the price of the call exactly offsets the price of the put, and the value of the risk reversal is zero. Hence, if the price of the risk reversal differs from 
zero, investors believe that foreign exchange movements are positively or negatively skewed (in risk-neutral terms). In other words, with constant risk premia, a more positive skewness would lead to a higher value of this risk reversal, and a more negative skewness would lead to a more negative value of the risk reversal. Of course, due to risk premia the riskneutral skewness is not necessarily equal to the physical skewness of exchange rate changes. Figures A1, A2, and A3 in the appendix depict the time series of exchange rates, interest rate differentials, skewness, and futures positions for the various currencies.

\section{Results}

\section{A. Summary Statistics and Simple Cross-Sectional Evidence}

A currency-by-currency perspective. We begin by highlighting some basic features of each currency separately in our summary statistics in table 1.

Table 1 shows that there is a positive cross-sectional correlation between the average interest rate differential $i_{t-1}^{*}-i_{t-1}$ and the average excess return $z_{t}$, which points to the violations of UIP in the data. For example, the currency with the most negative average excess return (JPY) of -0.004 also had the most negative average interest rate differential relative to the U.S. dollar of -0.007 . The currency with the highest excess return (NZD) of 0.013 also had the highest average interest rate differential of 0.009 .

It is also apparent from table 1 and from figure 2 that there is a clear negative cross-sectional correlation between skewness and the average

Table 1

Summary Statistics (Means)

\begin{tabular}{lrrrrrrrr}
\hline & AUD & CAD & JPY & NZD & NOK & CHF & GBP & EUR \\
\hline$\Delta s_{t}$ & -.003 & -.002 & -.003 & -.005 & -.002 & -.004 & -.004 & -.004 \\
$z_{t}$ & .009 & .004 & -.004 & .013 & .007 & -.001 & .009 & .003 \\
$i_{t-1}^{*}-i_{t-1}$ & .006 & .002 & -.007 & .009 & .005 & -.004 & .005 & -.001 \\
Futures positions & $\ldots$ & .059 & -.097 & $\ldots$ & $\ldots$ & -.067 & .052 & .031 \\
Skewness & -.322 & -.143 & .318 & -.297 & -.019 & .144 & -.094 & .131 \\
Risk reversals & -.426 & -.099 & 1.059 & -.467 & .350 & .409 & .009 & .329 \\
\hline
\end{tabular}

Note: Quarterly data, 1986-2006 (1998-2006 for risk reversals). $\Delta s_{t}$ is the quarterly change in the foreign exchange rate (units of foreign currency per U.S. dollar), $z_{t}$ is the return from investing in a long position in the foreign currency financed by borrowing in the domestic currency. Futures positions refers to the net long position in foreign currency futures of noncommercial traders. Risk reversals are the implied volatility difference between 1-month foreign currency call and put options, as described in the text. 
interest rate differential. This negative correlation between interest rate differentials and skewness shows that carry trades are exposed to negative skewness. An investor taking a carry trade investing in AUD financed by borrowing in USD during our sample period would have earned both the average interest rate differential of 0.006 plus the excess FX return on AUD relative to USD of 0.003 but would have been subject to the negative skewness of -0.322 , on average, of the daily return on the carry trade. An investor engaging in carry trades borrowing in JPY and investing in USD would have earned the interest rate differential of 0.007 minus the loss from the excess return of JPY relative to USD of 0.003 , but would have been subject to negative skewness of -0.318 .

The summary statistics also show that speculators are on average carry traders since there is a clear positive correlation between the average interest rate differential and the average net futures position of speculators in the respective currency. For example, speculators have large short positions in JPY, which has the most negative average interest rate differential.

Finally, the last row of table 1 shows the average value of risk reversals, for the subset of our sample from 1998 to 2006 for which we have risk-reversal data. Recall that the risk reversals provide a measure of the risk-neutral skewness in currency changes. The table and figure 2, bottom panel, show that countries with low interest rates tend to have positive risk-neutral skewness, while countries with high interest rates tend to have negative risk-neutral skewness.

A portfolio perspective. We also consider the cross-sectional relationship between carry and returns by looking at the performance of long-short portfolios where we vary the number of currencies included in the portfolio as reported in table 2. Specifically, our carry portfolio has long positions in the $k$ currencies with the highest interest rates

Table 2

Summary Statistics for Carry Trade Portfolio Returns

\begin{tabular}{|c|c|c|c|c|c|c|}
\hline & \multicolumn{2}{|c|}{1 Long, 1 Short } & \multicolumn{2}{|c|}{2 Long, 2 Short } & \multicolumn{2}{|c|}{3 Long, 3 Short } \\
\hline & Weekly & Quarterly & Weekly & Quarterly & Weekly & Quarterly \\
\hline Average return & .002 & .022 & .001 & .016 & .001 & .018 \\
\hline Standard deviation & .017 & .068 & .013 & .051 & .011 & .045 \\
\hline Skewness & -.717 & -.700 & -.537 & -.748 & -.695 & -.977 \\
\hline Kurtosis & 2.851 & .674 & 1.534 & .661 & 2.597 & 1.968 \\
\hline Annualized Sharpe ratio & .704 & .654 & .592 & .638 & .747 & .784 \\
\hline
\end{tabular}

Note: Quarterly data, 1986-2006, weekly data 1992-2006 for an equally weighted carry trade portfolio that is long in the $k=1,2,3$ currencies with the highest interest rates in the beginning of each week/quarter and short in the $k$ currencies with the lowest interest rates. 
in the beginning of each week (quarter) and short positions in the $k$ currencies with the lowest interest rates, where each currency is weighted equally and we consider $k=1,2,3$.

We see that the carry trade portfolios have large Sharpe ratios, negative skewness, and positive excess kurtosis. This means that the carry trade is profitable on average but has crash risk and fat tails.

We find no evidence that the negative skewness or excess kurtosis get diversified away as more currencies are added to the carry trade portfolio, at least with the simple equal-weighted portfolio strategies that we are considering here. The fact that skewness cannot easily be diversified away suggests that currency crashes are correlated across different countries, depending on interest rate differentials. This correlation could be driven by exposure to common (crash-) risk factors, and later we provide evidence that liquidity risk is one such driving risk factor.

To get a sense of the magnitudes, we can compare the skewness of the carry trade portfolio returns to the skewness of the U.S. stock market portfolio. Using the same sample periods for weekly and quarterly data as in table 2, the Center for Research in Security Prices value-weighted U.S. stock market index log return has skewness of -0.41 weekly and -0.88 quarterly, and annualized Sharpe ratios of 0.44 weekly and 0.41 quarterly. Hence, the skewness of the carry trade portfolio returns is roughly comparable to the magnitude of skewness of the stock market index. Further, consistent with our FX findings, equity skewness cannot be diversified away. On the contrary, diversified equity indices are more negatively skewed than individual stocks, which are positively skewed.

Hence, the UIP puzzle that the carry trade has a high average return and our finding of its negative skewness parallels the equity premium puzzle that the equity market has a high average return and a negative skewness. It also parallels the puzzling high average returns to shorting index options that come with significant negative skewness since the stock market crash in 1987. Hence the high returns of negatively skewed assets could be part of a general phenomenon, as argued in Brunnermeier, Gollier, and Parker (2007).

Another way to consider the magnitude of carry trade skewness is to ask whether it is a concern to professional traders in the FX market and, consequently, can be a factor driving currency risk premia. We believe it is. This is especially true since currency trades are often conducted by highly leveraged professional investors (Gagnon and Chaboud 2007; Galati et al. 2007). Hence, while the equity premium likely depends on individual investors' propensity to buy unlevered equity, the correction of UIP through currency carry trades largely depends on professional 
traders' willingness to lever up. When traders lever up, however, they risk forced liquidation due to a run: investors redeeming capital or counterparties refusing to finance the positions. Hence, a currency crash may force traders to eliminate or downsize (de-lever) their positions such that they fail to enjoy the subsequent rebound in the carry return. Further, as we show later, the carry trade often has losses precisely when traders have funding problems.

Summing up, our simple cross-sectional findings and our evidence from long-short portfolio returns point to a clear relationship between interest rates and currency crash risk. One might wonder, however, whether this is driven by fundamental differences across countries that lead to differences in both their interest rate and their currency risk. To control for country-specific effects, our analysis to follow focuses on time-series evidence with country fixed effects. As we shall see, the interest rate-skewness link is also strong in the time series, and several new interesting results arise. Indeed, the link between actual and risk-neutral skewness is more intricate in the time series, perhaps because of liquidity crises that come and go.

\section{B. Carry Predicts Currency Crashes}

To link the interest rate differential to currency trades and crash risk, we perform some simple predictive regressions as reported in table 3. First, we confirm that our data are consistent with the well-known violation of the UIP. We see that this is the case in the first column of table 3, which has the results of the regression of the return on a foreign currency investment financed by borrowing in USD in quarter $t+\tau$, on the interest rate differential in quarter $t$ :

$$
z_{t+\tau}=a+b\left(i_{t}^{*}-i_{t}\right)+\varepsilon_{t}
$$

We use a series of univariate pooled panel regressions with country fixed effects, which means that we work with within-country time variation of interest rate differentials and FX excess returns. We later consider a more dynamic vector-autoregressive specification. The table reports only the slope coefficient $b$. The results show the familiar results that currencies with high interest rate differentials to the USD have predictably high returns over the next quarters. This violation in UIP is also apparent from figure $\mathrm{A} 1$ in the appendix, which plots the exchange rates and interest rate differentials.

The second column in table 3 reports similar regressions, but now with speculators' futures positions as the dependent variable. The positive 
Table 3

Future Excess FX Return $z$, Futures Positions, and Skewness Regressed on $i_{t}^{*}-i_{t}$

\begin{tabular}{cccc}
\hline & FX Return $z$ & Futures & Skewness \\
\hline$t+1$ & 2.17 & 8.26 & -23.92 \\
& $(.78)$ & $(5.06)$ & $(3.87)$ \\
$t+2$ & 2.24 & 8.06 & -23.20 \\
& $(.70)$ & $(5.08)$ & $(3.71)$ \\
$t+3$ & 1.87 & 5.96 & -23.65 \\
& $(.66)$ & $(4.68)$ & $(3.87)$ \\
$t+4$ & 1.50 & 6.41 & -23.28 \\
& $(.63)$ & $(4.44)$ & $(4.65)$ \\
$t+5$ & 1.11 & 5.87 & -23.49 \\
& $(.52)$ & $(3.47)$ & $(5.05)$ \\
$t+6$ & .76 & 4.72 & -22.24 \\
& $(.48)$ & $(2.52)$ & $(5.00)$ \\
$t+7$ & .68 & 4.27 & -21.23 \\
& $(.49)$ & $(1.91)$ & $(4.09)$ \\
$t+8$ & .44 & 2.81 & -16.96 \\
& $(.55)$ & $(2.12)$ & $(4.03)$ \\
$t+9$ & .27 & .46 & -12.90 \\
& $(.63)$ & $(2.41)$ & $(3.45)$ \\
$t+10$ & -.04 & -.96 & -11.14 \\
& $(.78)$ & $(3.26)$ & $(3.74)$ \\
\hline
\end{tabular}

Note: Panel regressions with country fixed effects and quarterly data, 1986-2006. The regressions with Futures $t_{t+\tau}$ as the dependent variable include CAD, JPY, CHF, GBP, and EUR only (currencies for which we have futures positions data since 1986). Standard errors in parentheses are robust to within-time period correlation of residuals and are adjusted for serial correlation with a Newey-West covariance matrix with 10 lags.

coefficient for quarter $t+1$ indicates that there is carry trade activity in the futures market that tries to exploit the violations of UIP. When the interest rate differential is high (relative to the time-series mean for the currency in question), futures traders tend to take more long positions in that currency, betting on appreciation of the high interest rate currency. In the same way as the estimated coefficients in column 1 decline toward zero with increasing forecast horizon, the estimated coefficients for futures positions in column 2 also decline toward zero. Unlike column 1, however, we obtain only marginally significant coefficient estimates, indicating that there is quite a lot of statistical uncertainty about the time variation of futures positions in relation to movements in the interest rate differential. This somewhat noisy link between interest rates and speculator positions is also seen in figure A3 in the appendix.

The third column looks at conditional skewness. Negative conditional skewness can be interpreted as a measure of "crash risk" or "downside risk" inherent in carry trade strategies. We regress our within-quarter estimates of the skewness of daily FX rate changes in quarter $t+\tau$ on 
the interest rate differential at the end of quarter $t$. We see that interest rate differentials is a statistically highly significant negative predictor of skewness, and the coefficients decline to zero only slowly as the forecast horizon is extended. This implies that carry trades are exposed to crash risk: in times when the interest rate differential is high, and therefore carry trades look particularly attractive in terms of conditional mean return, the skewness of carry trade returns is also particularly negative. Thus, in times of high interest rate differentials, carry trade investors that are long currencies might "go up by the stairs" but occasionally "come down by the elevator." The interest rate-skewness link is also evident in the time-series plots in figure A2 in the appendix.

To illustrate the crash risk visually, we next estimate the distribution of excess currency return $z_{t}$ conditional on the interest rate differential $i_{t-1}^{*}-i_{t-1}$. Figure 3 plots kernel-smoothed density estimates with observations in the sample split into three groups based on the interest rate differential with country fixed effects. The top panel plots the distribution of quarterly returns, with observations split into $i_{t-1}^{*}-i_{t-1}<-0.005$,
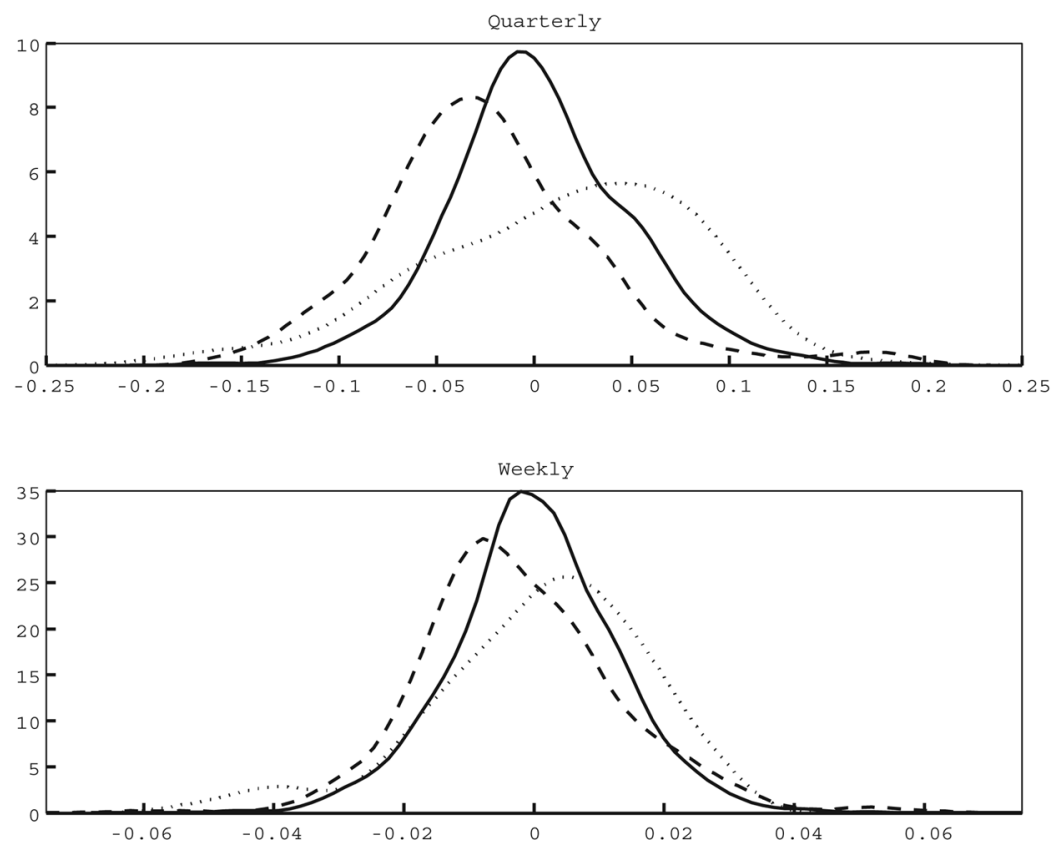

Fig. 3. Kernel density estimates of distribution of foreign exchange returns depending on interest rate differential. Interest rate differential groups after removing country fixed effects, quarterly (top panel): $<-.005$ (dashed line), -0.005 to 0.005 (solid line), $>0.005$ (dotted line); weekly (bottom panel): $<-0.01$ (dashed line), -0.01 to 0.01 (solid line), $>0.01$ (dotted line). 
$-0.005 \leq i_{t-1}^{*}-i_{t-1} \leq 0.005$, and $i_{t-1}^{*}-i_{t-1}>0.005$. The bottom panel plots the distribution of weekly returns with cutoffs for $i_{t-1}^{*}-i_{t-1}$ at -0.01 and 0.01 (the higher number of observations with weekly data allow us to move the cutoffs a bit further into the tails). Focusing on the top panel, it is apparent that when the interest rate differential is highly positive, the distribution of FX excess returns has a higher mean but also strong negative skewness, with a long tail on the left. When the interest rate differential is negative, we see the opposite, although somewhat more moderate, with a long tail to the right. Interestingly, even though the mean is higher with higher interest rate differentials, the most negative outcomes are actually most likely to occur in this case. Similarly, extremely positive realizations are most likely to occur when interest differentials are strongly negative. The bottom graph with weekly data shows broadly similar patterns. Hence, while our regressions focus on skewness measures derived from daily FX rate changes, the negative relationship between interest rate differentials and skewness also shows up at weekly and quarterly frequencies.

Figure 4 presents kernel-smoothed density estimates for the carry trade portfolio returns. For this graph, we focus on the equal-weighted
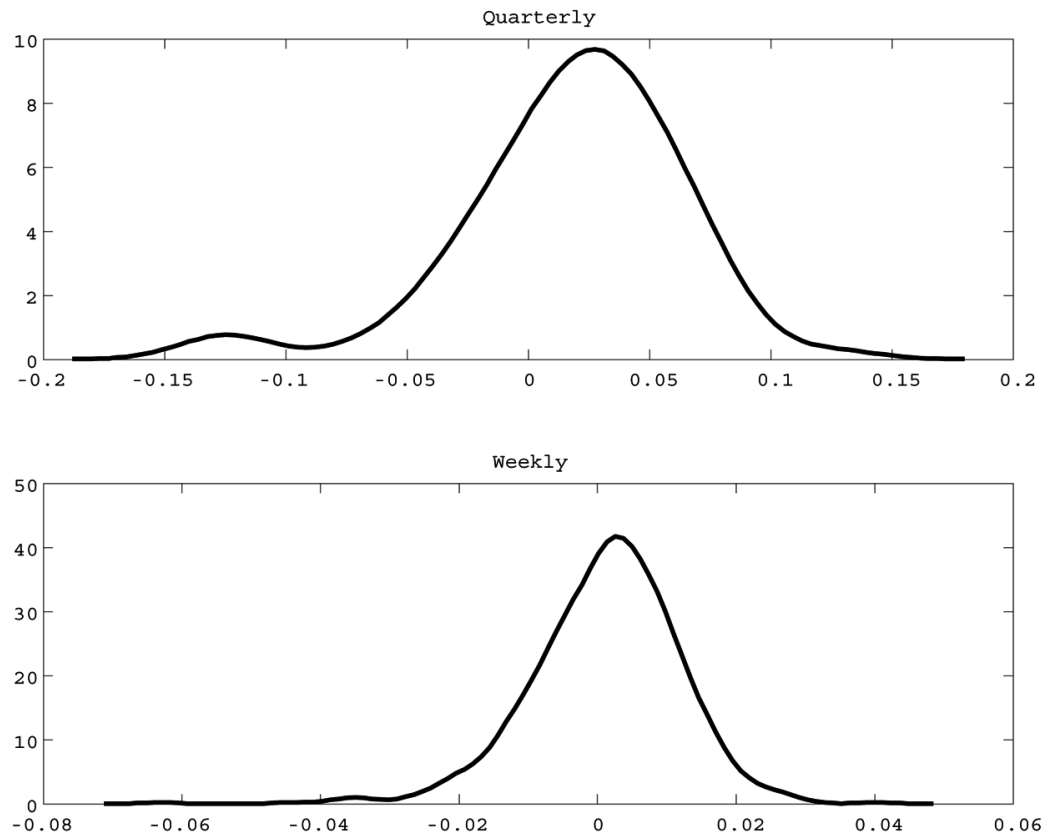

Fig. 4. Kernel density estimates of distribution of excess returns on a carry trade portfolio (long three high interest currencies, short three low interest currencies): top panel shows quarterly, while bottom panel shows weekly excess returns. 
portfolio that takes a long position every week (quarter) in the three highest interest rate currencies and a short position in the three lowest interest rate currencies. The figure clearly shows the fat left tail of the distributions, in particular at the quarterly frequency.

\section{Predictors of Currency Crashes Risk and the Price of Crash Risk}

We have seen that interest rate differentials predict skewness. We next look for other predictors of skewness and the price of skewness. In particular, we focus on how the level of carry trade activity and recent losses of carry trade strategies affect physical and risk-neutral conditional skewness.

Table 4 presents regressions of skewness measured within quarter $t+1$ or risk reversals measured at the end of quarter $t$, on time- $t$ variables. These regressions are again pooled panel regressions with country fixed effects. The first column once again shows that $i_{t}^{*}-i_{t}$ is a strong negative predictor of future skewness. In addition, the regression shows that skewness is persistent and that futures positions are negatively related to future skewness. The second column further shows that the past currency return $z_{t}$ negatively predicts skewness. This can be interpreted as currency gains leading to larger speculator positions and larger future crash risk. We also find that the currency gain variable "drives out" the futures position variable, because the futures positions at the end of quarter $t$ are strongly positively

Table 4

Forecasting Crashes and the Price of Crash Risk

\begin{tabular}{|c|c|c|c|c|c|}
\hline & Skewness $_{t+1}$ & Skewness $_{t+1}$ & Skewness $_{t+1}$ & $\operatorname{RiskRev}_{t}$ & $\operatorname{RiskRev}_{t}$ \\
\hline$i_{t}^{*}-i_{t}$ & $\begin{array}{c}-28.51 \\
(11.59)\end{array}$ & $\begin{array}{l}-22.18 \\
(12.59)\end{array}$ & $\begin{array}{c}-27.34 \\
(11.52)\end{array}$ & $\begin{array}{c}-15.51 \\
(29.20)\end{array}$ & $\begin{array}{l}-30.70 \\
(25.91)\end{array}$ \\
\hline$z_{t}$ & & $\begin{array}{r}-3.34 \\
(.60)\end{array}$ & $\begin{array}{r}-2.11 \\
(.69)\end{array}$ & & $\begin{array}{c}7.87 \\
(1.39)\end{array}$ \\
\hline Futures $_{t}$ & $\begin{array}{l}-.26 \\
(.12)\end{array}$ & $\begin{array}{c}.13 \\
(.15)\end{array}$ & $\begin{array}{c}.18 \\
(.14)\end{array}$ & $\begin{array}{l}1.16 \\
(.19)\end{array}$ & $\begin{array}{c}.27 \\
(.12)\end{array}$ \\
\hline Skewness $_{t}$ & $\begin{array}{l}.12 \\
(.05)\end{array}$ & $\begin{array}{l}.18 \\
(.05)\end{array}$ & $\begin{array}{l}.17 \\
(.05)\end{array}$ & $\begin{array}{l}.10 \\
(.09)\end{array}$ & $\begin{array}{c}-.02 \\
(.10)\end{array}$ \\
\hline $\operatorname{RiskRev}_{t}$ & & & $\begin{array}{c}-.16 \\
(.04)\end{array}$ & & \\
\hline$R^{2}$ & .12 & .18 & .21 & .20 & .41 \\
\hline
\end{tabular}

Note: Panel regressions with country fixed effects and quarterly data, 1998-2006, AUD, CAD, JPY, CHF, GBP, and EUR only. Standard errors in parentheses are robust to withintime period correlation of residuals and are adjusted for serial correlation with a NeweyWest covariance matrix with six lags. The reported $R^{2}$ is an adjusted $R^{2}$ net of the fixed effects. 
related to excess returns $z_{t}$ during that quarter (not reported in the table). Perhaps the past return is a better measure of speculator positions given the problems with the position data from the CFTC. Taken together, the results imply that crash risk of currencies is particularly high following high returns. Times when past returns are high also tend to be times when futures positions are high. This points to the possibility that part of the skewness of carry trade payoffs may be endogenously created by carry trade activity. Gains on carry trades lead to further build-up of carry trade activity, which then also increases the potential impact on FX rates of an unwinding of those carry trades after losses and which manifests itself in the data as negative conditional skewness.

In the third column we add risk reversals to the regression, and we obtain a surprising result. Controlling for interest rate differentials and the other variables in the regression, the relationship between risk reversals and future skewness is negative. This means that, everything else equal, a higher price for insurance against downside risk predicts lower future skewness. The bivariate correlation between risk reversals and skewness (untabulated) is positive, however, and so controlling for the other variables, in particular the interest rate differential, gives rise to the somewhat surprising negative coefficient. This is consistent with the interpretation that after a crash, speculators are willing to pay more for insurance, the price of insurance increases even though the future crash risk goes down, perhaps because of the smaller speculator positions. This parallels the market for catastrophe insurance as documented by Froot and O'Connell (1999) and Froot (2001).

The fourth and fifth columns in the table show the regression of risk reversals on the other variables. As the table shows, risk reversals have a negative relationship to $i_{t}^{*}-i_{t}$, just like physical/actual skewness in the first three columns. Although for risk reversals the relationship is not statistically significant, the point estimate suggests that risk reversals and physical skewness may have a common component related to to $i_{t}^{*}-i_{t}$. A stark difference exists, however, in their relationship to $z_{t}$. When a currency has had a high excess return in quarter $t$, this predicts a smaller (more negative) future physical skewness, but a larger risk reversal, and thus risk-neutral skewness, at the end of quarter $t$. This means that there is a wedge between the physical and risk-neutral skewness, that is, a skewness risk premium, that varies negatively with recent excess returns of the currency. This again points to the possibility that skewness is endogenously created by carry trade activity: when recent carry trade returns are strongly negative, carry trades get unwound, and there is less crash risk in the future. But, in addition to outright liquidation of 
carry trades, part of the unwinding seems to happen by carry traders buying insurance against downside risk, which drives up the price of insurance against crash risk, despite the fact that there is less negative conditional physical skewness.

\section{Are Carry Trades (De)Stabilizing?}

At horizons of more than one period, we focused so far on univariate forecasts with the interest rate differential as predictor. To shed some light on the dynamic relationships between interest rate differentials, FX rate changes, futures positions, and skewness over longer horizons, and to address the question whether carry traders are stabilizing or destabilizing, we estimate a vector autoregression (VAR). We first estimate

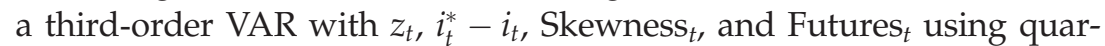
terly data from 1986 to 2006 for the five currencies for which we have futures positions data. Figure 5 reports impulse response function estimated from this $\operatorname{VAR}(3)$ system for shocks to the interest rate differential. The shocks underlying the impulse responses are based on a Choleski decomposition with the ordering $i_{t}^{*}-i_{t}, z_{t}$, Skewness ${ }_{t}$, and Futures ${ }_{t}$, the
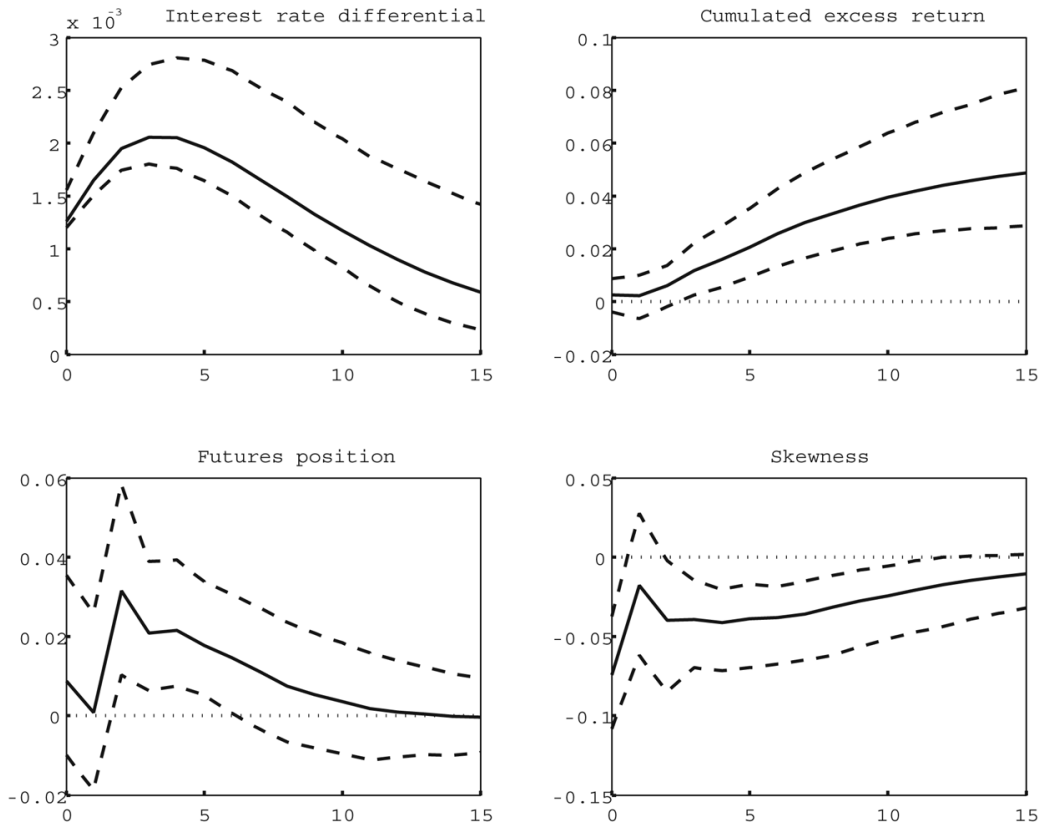

Fig. 5. Impulse response functions from VAR(3) for shock to interest rate differential with $90 \%$ confidence intervals. 
most important assumption being that shocks to the interest rate differential cause contemporaneous changes in the other three variables but shocks in the other three variables do not affect the VAR innovation of the interest rate differential. The figure also shows 90\% (bootstrap) confidence intervals following Kilian (1998), which account for the bias and skewness in the small-sample distribution of the impulse response functions.

The bottom left graph in figure 5 shows that the forecasted futures positions correspond closely to the forecasted interest rate differentials in the top left graph, consistent with higher interest rate differentials leading to more carry trade activity. The bottom right graph confirms that conditional skewness gets more negative following a positive shock to the interest rate differential, followed by slow reversion toward the mean. Overall, the VAR results confirm the basic facts from the univariate forecasting regressions in table 3.

The top left graph in figure 5 shows that after a positive shock to the interest rate differential, the interest rate differential keeps rising for about 4 quarters before it slowly reverts back to the mean. The top right graph shows that positive shocks to the interest rate differentials also lead to appreciation of the foreign exchange rate. If the UIP were to hold, the exchange rate would jump initially due to the interest rate shock in one currency and depreciate subsequently. Stated differently, the cumulative excess returns on carry trades would jump initially and stay constant afterward. Instead, as the figure shows, when the foreign interest rate increases relative to the domestic interest rate, substantial excess returns accumulate to a carry trader over this horizon since the foreign currency does not depreciate enough in the next 15 quarters to offset the persistently high interest rate differential.

VARs can also help analyze the important question of whether carry trades are profitable because exchange rates initially underreact to interest rate shocks or, alternatively, because exchange rates overreact as too many traders pile and then later fall back toward fundamentals as carry trades unwind their positions. The latter view would be consistent with the popular concern that carry trade activity creates "bubbles" by preventing investment currencies from depreciating as described by the UIP. Each individual speculator might find it optimal to hold on to his carry trades since he does not know when others unwind their positions. That is, each trader faces a synchronization risk as modeled in Abreu and Brunnermeier (2003). Consequently, a price-correcting crash occurs with a delay only when carry trades suddenly unwind. In contrast, the "underreaction view" argues that capital flows, and therefore also exchange rates, react sluggishly to shocks in interest rate differentials 
and that carry trade activity essentially helps to speed up the adjustment, as conjectured by Grossman (1995). One main reason for this sluggish behavior may be that carry traders demand a risk premium since they are exposed to "crash risk" in the form of negative skewness of carry trade returns as we have documented. Under this hypothesis, currency crashes in which carry traders face losses tend to move the exchange rate further away from fundamentals (assuming that the fundamental exchange rate is consistent with UIP).

These two hypotheses make different predictions about the behavior of the impulse response of the cumulative excess returns of the VAR, as illustrated in the top left panel. As noted above, UIP predicts that higher interest rate leads to a jump up in the carry return and then a flat $\mathrm{cu}-$ mulative return from then onward as the future interest rate differentials are compensated by exchange rate depreciation. Underreaction implies that the initial jump is small and that the positive returns continue for a while. Finally, overreaction implies that the returns are positive for a while and then turn negative, that is, the cumulative return should be hump shaped. As seen in figure 5, our estimated VAR is consistent with an initial underreaction. It is also possible that there is a long-run overreaction (or bubble). However, we cannot make a definite statement, because long-run predictions are difficult to test econometrically, for example, because the conclusion can be quite sensitive to the specification of the VAR. In particular, to properly capture a hump shape in cumulative excess returns may require many lags in the VAR. But including many lags would make estimates imprecise and hence make it impossible to draw any inference about long-run impulse responses with much statistical confidence.

Importantly, we can test the hypothesis in an alternative way, namely, by considering how much the exchange rate moves in response to interest rate shocks relative to what UIP predicts. Said differently, UIP predicts not only that the cumulative return should jump up and then be flat, it can also be used to predict how much the exchange rate should jump, and we can compare this to the VAR-estimated moves to look for under- or overreaction. To do this, we need to make additional assumptions, namely, that the real exchange rate is stationary.

We add inflation since it is more natural to complement the UIP with the assumption that the PPP holds in the long run and that the real exchange rate is stationary (rather than assuming a stationary nominal exchange rate). In other words, the interest rate shock will affect future inflation, and this will ultimately affect exchange rates. Under the assumption that the exchange rate is stationary, the UIP-predicted magnitude of the logexchange rate change is the sum of all future log-interest rate differentials. 
For example, if there is a surprise increase in interest rates in Japan relative to those in the United States,

$$
i_{t}^{*}-i_{t}-E_{t-1}\left[i_{t}^{*}-i_{t}\right]>0
$$

then, under UIP,

$$
z_{t}=\sum_{\tau=0}^{\infty}\left(E_{t}\left[i_{t+\tau}^{*}-i_{t+\tau}\right]-E_{t-1}\left[i_{t+\tau}^{*}-i_{t+\tau}\right]\right)-\left(E_{t}[\bar{s}]-E_{t-1}[\bar{s}]\right),
$$

where $\bar{s}$ is the long-run level of the nominal exchange rate. Further, we use our assumption of a stationarity of the log real exchange rate, defined as $s_{t}-p_{t}^{*}+p_{t}$, where $p_{t}^{*}$ and $p_{t}$ are the foreign and domestic price levels, respectively. This yields a total UIP-predicted initial exchange rate move of

$$
\begin{aligned}
z_{t}= & \sum_{\tau=0}^{\infty}\left(E_{t}\left[i_{t+\tau}^{*}-i_{t+\tau}\right]-E_{t-1}\left[i_{t+\tau}^{*}-i_{t+\tau}\right]-E_{t}\left[\pi_{t+\tau+1}^{*}-\pi_{t+\tau+1}\right]\right. \\
& \left.+E_{t-1}\left[\pi_{t+\tau+1}^{*}-\pi_{t+\tau+1}\right]\right)
\end{aligned}
$$

where $\pi_{t+\tau}^{*}-\pi_{t+\tau}$ is the inflation rate differential.

After incorporating the inflation differential, we reestimate the dynamics with a more parsimonious VAR to keep the number of parameters manageable. Specifically we leave out Futures and Skewness, since these variables have little predictive power for the other variables in the VAR, so their exclusion has little effect on the estimated impulse response of cumulative returns. Figure 6 presents the impulse response functions estimated from this second VAR(3) that includes inflation. The ordering of shocks is now $i_{t}^{*}-i_{t}, \pi_{t}^{*}-\pi_{t}$, and then $z_{t}$. The dashed horizontal line in the lower left panel is the cumulated excess return predicted by the UIP, and its initial jump reflects the present value of the future real interest rate differentials as predicted by the VAR. It is apparent from figure 6 that the cumulative excess returns-and hence the exchange rate-initially underreacts. If there were more carry trade activity immediately following the shock to the interest rate differential, then this would tend to push up the exchange rate toward the reaction implied by UIP. While our findings do not rule out long-term overreactions-due to limits on our statistical power and issues with the specification of the VAR — our combined results suggest that, at least for a time period after a shock to interest rates, carry trade activity pushes FX rates toward fundamentals rather than away from it.

\section{E. Liquidity Risk and Unwinding of Carry Trades}

Our analysis so far raised the possibility that unwinding of carry trades could explain some of the skewness of the returns to carry trades and 

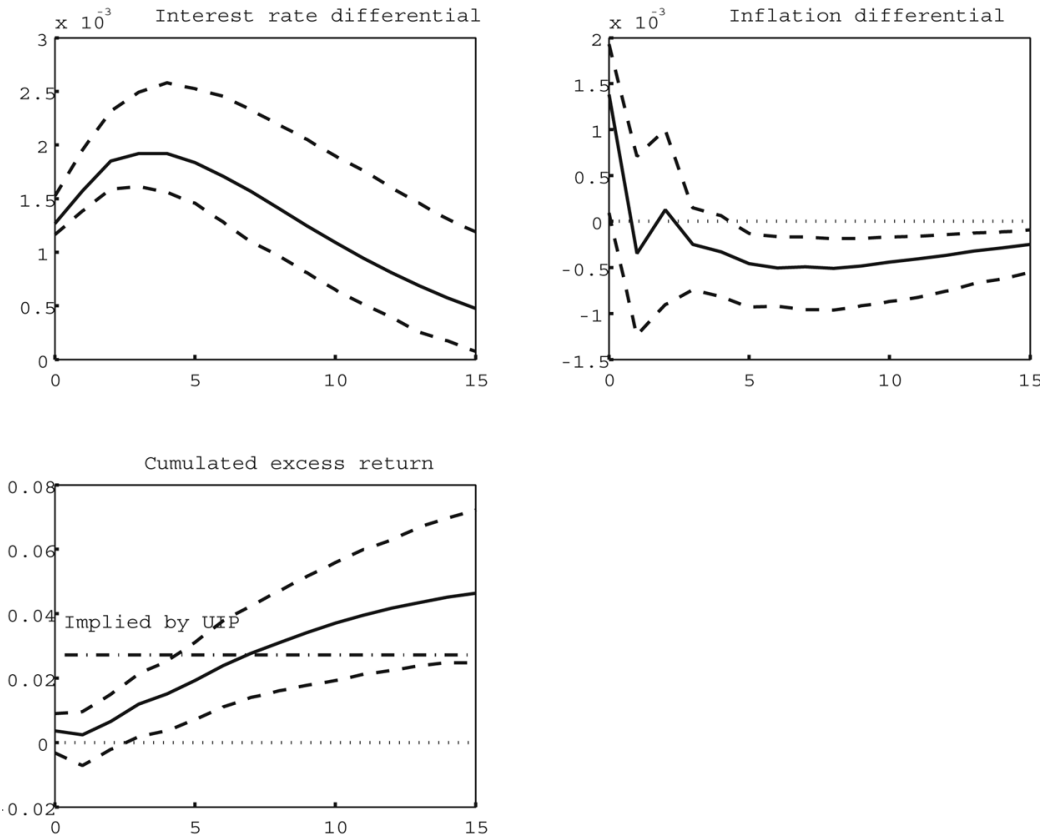

Fig. 6. Impulse response functions from VAR(3) for shock to interest rate differential with $90 \%$ confidence intervals.

that the negative skewness of carry trade payoffs combined with the threat of forced unwinding could be a deterrent to engaging in large highly levered carry trade activity that would help eliminate UIP violations. To better understand these interrelationships, we try to identify states of the world in which speculators are likely to be forced to unwind positions due to losses, capital redemptions, increased margin, or reduced risk tolerance.

Identifying such states of the world empirically is not an easy task. Ideally, we would want a measure for speculators' willingness and ability to put capital at risk, but that could depend on many (largely unobservable) factors, including tightness of margin constraints, value-at-risk limits, recent returns of carry trade strategies, liquidity spillovers from other markets, the amount of risk capital devoted to carry trade strategies, and others. We use two measures: (i) the CBOE VIX option implied volatility index as an observable proxy that should be correlated with at least several of these factors and (ii) the TED spread, the difference between the 3-months LIBOR eurodollar rate and the 3-months T-Bill rate. The LIBOR 
rate reflects uncollateralized lending in the interbank market, which is subject to default risk, while the T-Bill rate is riskless since it is guaranteed by the U.S. government. When banks face liquidity problems the TED spread typically increases, and the T-Bill yield often falls due to a "flight to liquidity" or "flight to quality."

Prior research has shown that the VIX index is a useful measure of the "global risk appetite" not only in equity, and equity-options markets, but also in corporate credit markets (Collin-Dufresne, Goldstein, and Martin 2001) and in other, seemingly unrelated, markets. For example, Pan and Singleton (2008) find that the VIX is strongly related to the variation in risk premiums in sovereign credit default swaps. Moreover, many of the financial crises of recent years, for example, the Russian/ LTCM crisis of 1998, or the financial market turmoil in the summer of 2007, were accompanied by strong increases in the VIX.

Table 5 presents pooled panel regressions with country fixed effects. Note that so far, we could ignore the direction of the carry trade, since the interest rate differential, futures positions, and payoffs from exchange rate movements switch signs when the direction of the trade is reversed. This is not the case with the VIX or TED spread, and hence we interact these two variables with the sign of the interest rate differential, $\operatorname{sign}\left(i_{t}^{*}-i_{t}\right)$.

The first two columns show that $\Delta$ Futures $_{t}$ and $\Delta$ Futures $_{t+1}$ are both significantly negatively related to signed $\Delta \mathrm{VIX}_{t}$, meaning that carry

\section{Table 5}

Sensitivity of Weekly Carry Trade Positions, Price of Skewness Insurance, and Carry Trade Returns to Changes in VIX

\begin{tabular}{|c|c|c|c|c|c|c|}
\hline & $\Delta$ Futures $_{t}$ & $\Delta$ Futures $_{t+1}$ & $\Delta \operatorname{RiskRev}_{t}$ & $\Delta \operatorname{RiskRev}_{t+1}$ & $z_{t}$ & $z_{t+1}$ \\
\hline$\Delta \operatorname{VIX}_{t} \times \operatorname{sign}\left(i_{t-1}^{*}-i_{t-1}\right)$ & $\begin{array}{r}-1.47 \\
(.77)\end{array}$ & $\begin{array}{r}-1.29 \\
(.57)\end{array}$ & $\begin{array}{c}-5.33 \\
(2.64)\end{array}$ & $\begin{array}{c}-2.74 \\
(3.39)\end{array}$ & $\begin{array}{c}-.43 \\
(.11)\end{array}$ & $\begin{array}{r}-.03 \\
(.11)\end{array}$ \\
\hline Futures $_{t-1}$ & $\begin{array}{c}-.09 \\
(.01)\end{array}$ & $\begin{array}{c}-.10 \\
(.01)\end{array}$ & & & & \\
\hline $\operatorname{RiskRev}_{t-1}$ & & & $\begin{array}{c}-.16 \\
(.02)\end{array}$ & $\begin{array}{c}-.11 \\
(.02)\end{array}$ & & \\
\hline$R^{2}$ & .04 & .06 & .08 & .04 & .00 & -.00 \\
\hline
\end{tabular}

Note: Panel regressions with country fixed effects and weekly data, 1992-2006 (1998-2006 for risk reversals), AUD, CAD, JPY, CHF, GBP, and EUR only (only currencies for which we have futures positions data since 1992). VIX is the CBOE volatility index. $z_{t}$ is the return from investing in a long position in the foreign currency financed by borrowing in the domestic currency. Standard errors in parentheses are robust to within-time period correlation of residuals and are adjusted for serial correlation with a Newey-West covariance matrix with 12 lags for futures, 6 for risk reversals, and 4 for returns. The reported $R^{2}$ is an adjusted $R^{2}$ net of the fixed effects. 
trades are unwound in times when the VIX increases. At the same time, as shown in columns 3 and 4, risk reversals are also negatively related to signed $\Delta$ VIX $_{t}$. The price of insurance of carry trades against crash risk therefore increases in times of rising VIX. Finally, column 5 shows that carry trades loses money on average in times of rising VIX.

Taken together, unwinding of carry trades in response to decreases in global risk appetite can jointly explain the results in table 5: when traders risk tolerance declines, carry trades are unwound, which leads to a reduction in the futures positions in investment currencies, an increase in the price of insurance against crash risk, and bad payoffs of carry trades. The dependence of carry trade payoffs on changes in the VIX, which according to prior research is driven to a large extent by variations in "risk appetite," also suggests that part of the movement in investment and funding currencies is driven by changing risk tolerance of traders and that crashes may occur endogenously as part of the trading process with leveraged and imperfectly capitalized traders.

We replicate the same exercise with our second measure of funding liquidity risk, the TED spread (table 6). It is reassuring that the coefficient on the signed TED spread coincides with the sign of the coefficient on the signed VIX in table 5. However, the coefficients are not statistically significant. We do find a significant negative relationship for predicting the

\section{Table 6}

Sensitivity of Weekly Carry Trade Positions, Price of Skewness Insurance, and Carry Trade Returns to Changes in the LIBOR-T-Bill (TED) Spread

\begin{tabular}{|c|c|c|c|c|c|c|}
\hline & $\Delta$ Futures $_{t}$ & $\Delta$ Futures $_{t+1}$ & $\Delta \operatorname{RiskRev}_{t}$ & $\Delta \operatorname{RiskRev}_{t+1}$ & $z_{t}$ & $z_{t+1}$ \\
\hline$\Delta \mathrm{TED}_{t} \times \operatorname{sign}\left(i_{t-1}^{*}-i_{t-1}\right)$ & $\begin{array}{l}-.48 \\
(2.27)\end{array}$ & $\begin{array}{l}-1.92 \\
(1.85)\end{array}$ & $\begin{array}{c}-.71 \\
(10.02)\end{array}$ & $\begin{array}{l}-25.05 \\
(13.89)\end{array}$ & $\begin{array}{l}-.27 \\
(.35)\end{array}$ & $\begin{array}{c}-.57 \\
(.31)\end{array}$ \\
\hline Futures $_{t-1}$ & $\begin{array}{l}-.09 \\
(.01)\end{array}$ & $\begin{array}{c}-.10 \\
(.01)\end{array}$ & & & & \\
\hline $\operatorname{RiskRev}_{t-1}$ & & & $\begin{array}{l}-.16 \\
(.02)\end{array}$ & $\begin{array}{l}-.11 \\
(.02)\end{array}$ & & \\
\hline$R^{2}$ & .04 & .06 & .08 & .04 & .00 & .00 \\
\hline
\end{tabular}

Note: Panel regressions with country fixed effects and weekly data, 1992-2006 (1998-2006 for risk reversals), AUD, CAD, JPY, CHF, GBP, and EUR only (only currencies for which we have futures positions data since 1992). TED is the 3-month USD LIBOR minus the 3-month T-Bill yield. $z_{t}$ is the return from investing in a long position in the foreign currency financed by borrowing in the domestic currency. Standard errors in parentheses are robust to withintime period correlation of residuals and are adjusted for serial correlation with a NeweyWest covariance matrix with 12 lags for futures, 6 for risk reversals, and 4 for returns. The reported $R^{2}$ is an adjusted $R^{2}$ net of the fixed effects. 
change of next week's risk reversal, $\Delta \operatorname{RiskRev}_{t+1}$ and, marginally so, for next week's excess return, $z_{t+1}$. Thus, while an increase in equity-optionbased VIX in table 5 is associated with a contemporaneous statistically significant reaction of risk reversals and carry trade excess returns, a change in the TED spread is only related to risk reversals and carry trade returns with a week delay.

Another way of viewing these findings is that the VIX and TED are common risk factors for exchange rates signed by their interest rate differentials. This helps explain why a diversified carry portfolio continues to have crash risk (negative skewness) and fat tails (excess kurtosis) as we showed in table 2 . Indeed, many of the legs to the carry trade can lose money at the same time since the carry trades are exposed to a systematic crash risk that is related to "flight to liquidity" or a "flight to quality." Therefore, we would also expect that the return of the diversified carry trade has negative loadings on $\Delta \mathrm{VIX}_{t}$ and $\Delta \mathrm{TED}_{t}$. Table 7 presents those loadings for the three-long, three-short carry trade portfolio described earlier, and, indeed, the relationships are similar to those in the panel regressions: $\Delta \mathrm{VIX}_{t}$ has a strong contemporaneous correlation, but not much effect in the following week, while $\Delta \mathrm{TED}_{t}$ has a stronger predictive relationship to the return in the following week and a smaller contemporaneous effect.

\section{F. Liquidity Risk Helps Explain Deviations from UIP}

Given the strong contemporaneous impact of VIX on excess returns of carry trades, it is natural to ask whether the signed VIX and possibly the

\section{Table 7}

Sensitivity of Weekly Carry Trade Portfolio Excess Returns to Changes in the VIX and the LIBOR-T-Bill (TED) Spread

\begin{tabular}{lcccc}
\hline & Return $_{t}$ & Return $_{t+1}$ & Return $_{t}$ & Return $_{t+1}$ \\
\hline$\Delta \mathrm{VIX}_{t}$ & -.94 & -.07 & & \\
$\Delta \mathrm{TED}_{t}$ & $(.25)$ & $(.23)$ & -1.21 & -1.57 \\
$R^{2}$ & & & $(.84)$ & $(.56)$ \\
\hline
\end{tabular}

Note: Regressions with weekly data for the three long, three short carry trade portfolio, 1992-2006. TED is the 3-month USD LIBOR minus the 3-month T-Bill yield. Standard errors in parentheses are adjusted for serial correlation with a Newey-West covariance matrix with four lags. The reported $R^{2}$ is an adjusted $R^{2}$. 
signed TED spread might help to forecast future excess returns on carry trades in various quarters in the future. To the extent that contemporaneous reaction of carry trade returns reflect a change in risk premiums, one would expect that they should help forecast carry trade returns (assuming sufficient statistical power). To answer this question, we replicate our earlier forecasting regressions shown in table 3 but also include the signed VIX (or signed TED spread) as predictor. Table 8 shows two interesting facts: First, the coefficients of the interest rate differential in the forecasting regressions with VIX are about half of that in table 3 and less statistically significant. Second, the signed VIX is a statistically significant predictor for several quarters in the future, albeit not for the immediate next quarter. Put together with the results of table 5 (col. 5), this suggests that an increase in VIX contemporaneously reduces returns on carry trades but leads to higher returns some quarters out. The forecasting regressions with the TED spread show a similar

Table 8

Future Excess FX Return $z$ Regressed on $i_{t}^{*}-i_{t}$ and Its Interaction with VIX or TED

\begin{tabular}{|c|c|c|c|c|}
\hline \multirow[b]{2}{*}{ Excess Return at } & \multicolumn{2}{|r|}{ Forecast with VIX } & \multicolumn{2}{|c|}{ Forecast with TED } \\
\hline & $i_{t}^{*}-i_{t}$ & $\operatorname{VIX}_{t} \times \operatorname{sign}\left(i_{t-1}^{*}-i_{t-1}\right)$ & $i_{t}^{*}-i_{t}$ & $\operatorname{TED}_{t} \times \operatorname{sign}\left(i_{t-1}^{*}-i_{t-1}\right)$ \\
\hline \multirow[t]{2}{*}{$t+1$} & 1.35 & .29 & 2.58 & -.62 \\
\hline & $(1.36)$ & $(.26)$ & $(1.01)$ & $(.45)$ \\
\hline \multirow[t]{2}{*}{$t+2$} & 1.37 & .35 & 2.27 & -.04 \\
\hline & $(1.17)$ & $(.18)$ & $(.91)$ & $(.50)$ \\
\hline \multirow[t]{2}{*}{$t+3$} & .75 & .53 & 1.40 & .72 \\
\hline & $(1.20)$ & $(.23)$ & $(.90)$ & $(.58)$ \\
\hline \multirow[t]{2}{*}{$t+4$} & .63 & .53 & .96 & .84 \\
\hline & $(1.22)$ & $(.23)$ & $(.90)$ & $(.59)$ \\
\hline \multirow[t]{2}{*}{$t+5$} & .93 & .31 & 1.04 & .11 \\
\hline & $(.82)$ & $(.16)$ & $(.58)$ & $(.29)$ \\
\hline \multirow[t]{2}{*}{$t+6$} & .63 & .29 & .18 & .88 \\
\hline & $(.65)$ & $(.11)$ & $(.48)$ & $(.30)$ \\
\hline \multirow[t]{2}{*}{$t+7$} & .23 & .34 & .23 & .70 \\
\hline & $(.90)$ & $(.16)$ & $(.57)$ & $(.28)$ \\
\hline \multirow[t]{2}{*}{$t+8$} & .05 & .31 & .46 & -.03 \\
\hline & $(.83)$ & $(.17)$ & $(.64)$ & $(.40)$ \\
\hline \multirow[t]{2}{*}{$t+9$} & .28 & .0954 & .41 & -.21 \\
\hline & $(.79)$ & $(.18)$ & (.68) & $(.34)$ \\
\hline \multirow[t]{2}{*}{$t+10$} & .30 & .02 & -.25 & .33 \\
\hline & $(.87)$ & (.17) & (.77) & $(.40)$ \\
\hline
\end{tabular}

Note: Panel regressions with country fixed effects and quarterly data, 1990-2006 for the regressions with VIX, 1986-2006 for the regressions with TED. Standard errors in parentheses are robust to within-time period correlation of residuals and are adjusted for serial correlation with a Newey-West covariance matrix with 10 lags. 
pattern, although the TED spread is only significant for lags of 6 or 7 quarters out.

\section{G. Predictable Comovement of FX Rates}

If part of the movements in investment and funding currencies are driven by changing risk tolerance of traders, then this should also affect the comovement of FX rates. For example, if carry traders unwind in response to declining risk tolerance, and their unwinding has price impact, then this should cause funding currencies to comove positively with funding currencies and investment currencies with investment currencies. Thus, everything else equal, currencies with similar interest rates should comove closely, while currencies with very different interest rates should have little, or even negative, comovement.

To test this, we calculate the pairwise correlation of daily $\mathrm{FX}$ rate changes within nonoverlapping 13-week periods, and we regress these correlations on $\left|i_{1}^{*}-i_{2}^{*}\right|$, the absolute interest rate differential between the countries in each pair at the start of the 13-week period. The results are shown in table 9.

Table 9

Correlation of FX Rate Changes and Magnitude of Interest Rate Differentials

\begin{tabular}{lcccc}
\hline & $(1)$ & $(2)$ & $(3)$ & $(4)$ \\
\hline$\left|i_{1}^{*}-i_{2}^{*}\right|$ & -10.89 & -6.62 & -16.39 & -13.41 \\
& $(3.81)$ & $(3.62)$ & $(4.05)$ & $(6.41)$ \\
$\rho\left(i_{1}^{*}, i_{2}^{*}\right)$ & .63 & .28 & .70 & .32 \\
& $(.16)$ & $(.08)$ & $(.17)$ & $(.08)$ \\
Average $\rho\left(\Delta s_{1}, \Delta s_{2}\right)$ & 2.54 & 2.56 & & \\
& $(.08)$ & $(.08)$ & & Yes \\
Time fixed effects & & & & Yes \\
Country-pair fixed effects & .18 & .36 & .05 & Yes \\
& & & 03 \\
\hline
\end{tabular}

Note: Panel regressions, 1992-2006. The dependent variable is the pairwise correlation of daily FX rate changes, estimated within nonoverlapping 13-week periods. $\left|i_{1}-i_{2}\right|$ is the absolute pairwise interest rate differential at the start of the 13-week period. $\rho\left(i_{1}, i_{2}\right)$ is the correlation of 5-day interest rate changes, estimated with overlapping windows, within each 13-week period. Average $\rho\left(\Delta s_{1}, \Delta s_{2}\right)$ is the cross-sectional average of all pairwise correlations of daily FX rate changes within each nonoverlapping 13-week period. The reported $R^{2}$ is an adjusted $R^{2}$ net of the fixed effects. 
Of course, some countries might have similar interest rates and highly correlated FX rates for reasons other than the effects of carry trades. We control for these other reasons in several ways. First, we include $\rho\left(i_{1}^{*}, i_{2}^{*}\right)$ as a control variable, the correlation of 5-day interest rate changes, estimated with overlapping windows, within each 13-week period. This variable proxies for correlated monetary policy. Second, we also run a specification where we include country-pair fixed effects. This should take care of other unobserved time-constant reasons for a country pair to have high or low correlation of FX rates. For example, CAD and AUD FX rates have a high correlation, due to the common exposure of their economies to mining, but this common exposure is largely absorbed by the fixed effect. Finally, to make sure that the results are not driven by the exposure of all exchange rates to a common factor, and time variation in the volatility of this common factor, which could lead to common variation in all pairwise correlations, we include either time dummies or the cross-sectional average of all pairwise correlations of daily FX rate changes within each nonoverlapping 13-week period, denoted by "Average $\rho\left(\Delta s_{1}, \Delta s_{2}\right)$."

The estimates in table 9 show that there is a strong negative relationship between $\left|i_{1}^{*}-i_{2}^{*}\right|$ and the FX rate correlation. A reduction of $1 \%$ in the interest rate differential is associated with an increase of the FX rate correlation of more than 0.1 . The results are fairly similar for all specifications shown in the table. In particular, the specification with country fixed effects shows that this relationship holds even if we only consider within-country-pair variation. In other words, when the interest rate differential for a given country pair is lower than it is on average for this country pair, then the correlation of the FX rate is higher than it is on average for this country pair. This feature of the data is also consistent with the view we suggested above, that is, that the buildup and unwinding of carry trades associated with changes in traders' risk tolerance has an effect on FX rates.

\section{Conclusion}

This paper provides evidence of a strong link between currency carry and currency crash risk: investing in high interest rate currencies while borrowing in low interest rate currencies delivers negatively skewed returns. We document that speculators invest in high-carry currencies and argue that currency crashes are linked to the sudden 
unwinding of these carry trades. Consistent with models in which the erosion of capital increases insurance premia, we find that the price of protecting against a crash in the aftermath of one increases despite the fact that a subsequent crash is less likely. Further, we document that currency crashes are positively correlated with increases in implied stock market volatility VIX and the TED spread, indicators of funding illiquidity, among other things. This could be the outcome of a setting in which higher volatility leads to lower available speculator capital due to higher margins and capital requirements, inducing traders to cut back on their carry trade activities. Moreover, we find that a higher VIX predicts higher carry returns going forward and that controlling for this effect reduces the FX return predictability of interest rates, that is, it helps resolve the UIP violation. Finally, our finding that currencies with similar interest rates comove with each other, controlling for other effects, further suggests that carry trades affects exchange rate movements.

Overall, our results are consistent with the view that macroeconomic fundamentals determine which currencies have high and low interest rates and the long-run currency levels, while illiquidity and capital immobility lead to short-run currency underreaction to changes in fundamentals and occasional currency crashes due to liquidity crises. Hence, our findings call for new macroeconomic models in which risk premia are affected by market liquidity and funding liquidity issues, not just shocks to productivity, output, or the utility function. 


\section{Appendix}

\section{Time Series for Different Currencies}
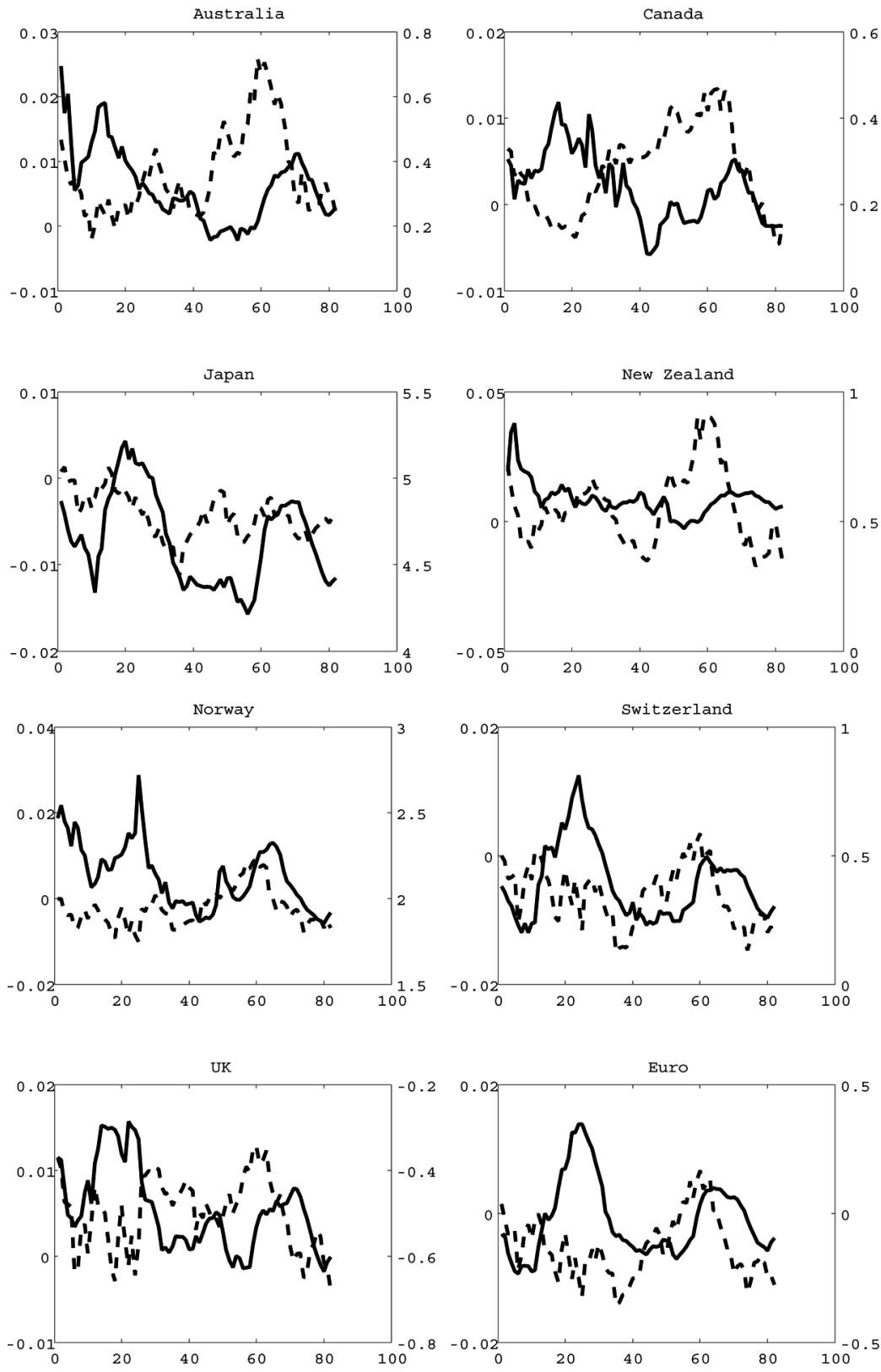

Fig. A1. Log interest rate differentials (solid line, left axis) and log FX rate (dashed line, right axis). 

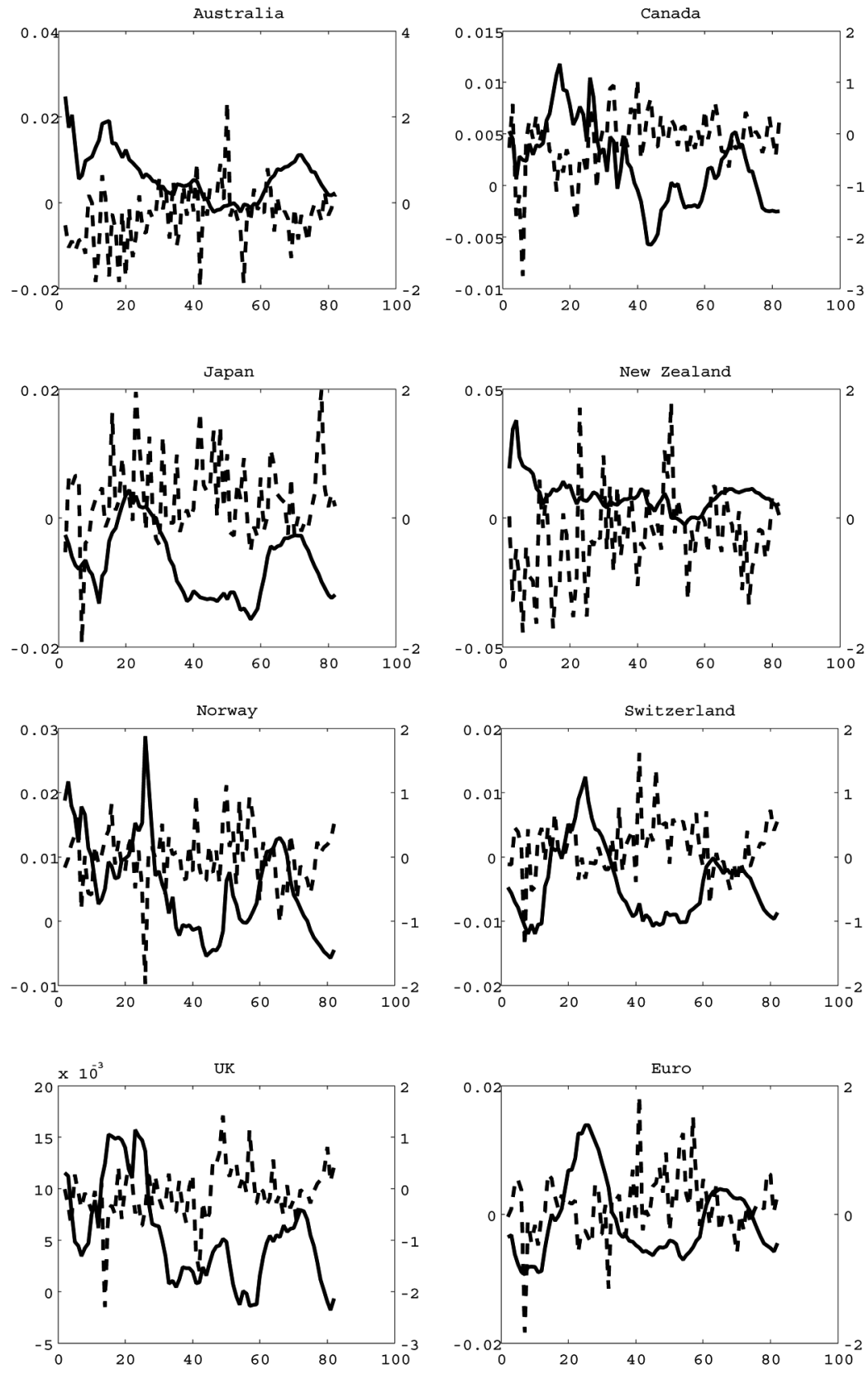

Fig. A2. Lagged log interest rate differentials (solid line, left axis) and quarterly skewness of daily log FX rate change (dashed line, right axis). 

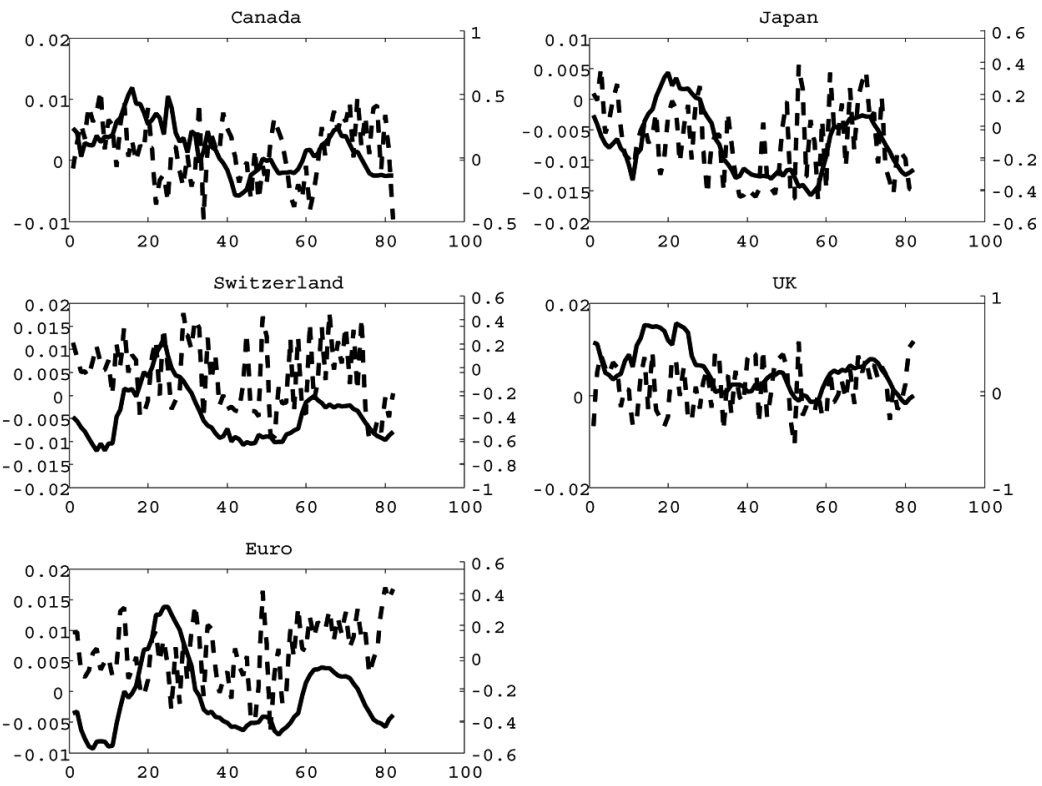

Fig. A3. Log interest rate differentials (solid line, left axis) and futures positions of noncommercial traders (dashed line, right axis).

\section{Endnotes}

Special thanks goes to Craig Burnside, Gabriele Galati, Jean Imbs, Jakub Jurek, Hanno Lustig, Igor Makarov, Michael Melvin, Martin Oehmke, Nikolai Roussanov, Adrien Verdelhan, and the editors Daron Acemoglu, Ken Rogoff, and Mike Woodford. We are also grateful to comments from seminar participants at New York University, BGI, International Monetary Fund, and conference participants at the German Economists Abroad conference, the American Economics Association meeting 2008, NBER Behavioral Finance meetings, and P. Woolley Center at the London School of Economics. Brunnermeier acknowledges financial support from the Alfred P. Sloan Foundation.

1. While the Long Term Capital Management (LTCM) debacle, which occurred between the end of August and early September 1998, is not completely unrelated, it is quite distinct from the U.S. dollar/Japanese yen crash on October 7 and 8, 1998. Note also that the Fed's surprise interest rate cut of $0.5 \%$ happened only on October 15.

2. If the interest rate increase is due an increase in total factor productivity the additional inflow of capital is efficient. However, if the country's central bank increases the interest rate to slow domestic demand in order to curb inflationary pressures, additional capital inflow is counterproductive. In this case the central bank faces a dilemma-known in International Monetary Fund circles as the "Tosovský Dilemma," named for Joseph Tosovský, former Central Bank governor of the Czech Republic, whose attempts to dampen domestic demand with higher interest rates were largely undone by larger capital inflows.

3. It should also be noted that the option-implied skewness derived from risk reversals is immune to peso problems, while the realized skewness measure is not.

4. See also Barberis and Huang (2007) and Brunnermeier, Gollier, and Parker (2007), in which belief distortions create a preference for positive skewness, resulting in higher expected returns for assets and trading strategies with negatively skewed payoffs.

5. Taking the derivative of the option price with respect to the spot exchange rate gives the option delta. An at-the-money call with exercise price at the current forward exchange 
rate has a call delta of about a half, that is, the option price reaction is only half of the change in the underlying exchange rate. The label $25 \Delta$ refers to how far out of the money the options are, namely, the strike of the call is at a call delta of 0.25 , and the strike of the put is at a call delta of 0.75 .

6. Both options that form the risk reversal can be priced using the Garman and Kohlhagen (1983) formula, which is a modified Black-Scholes formula taking into account that both currencies pay a continuous yield given by their respective interest rates. Inputting the implied volatility and other parameters into the Garman and Kohlhagen (1983) formula gives the option price in dollar terms, but the options are quoted in terms of implied volatility.

\section{References}

Abreu, D., and M. K. Brunnermeier. 2003. "Bubbles and Crashes." Econometrica 71, no. 1:173-204.

Bacchetta, P., and E. van Wincoop. 2007. "Infrequent Portfolio Decisions: A Solution to the Forward Discount Puzzle." Working paper, University of Lausanne.

Barberis, N. C., and M. Huang. 2007. "Stocks as Lotteries: The Implications of Probability Weighting for Security Prices." Working paper, Yale University.

Bhansali, V. 2007. "Volatility and the Carry Trade." Journal of Fixed Income 17, no. 3:72-84.

Brunnermeier, M. K., C. Gollier, and J. Parker. 2007. “Optimal Beliefs, Asset Prices and the Preference for Skewed Returns." American Economic Review Paper and Proceedings 97, no. 2:159-65.

Brunnermeier, M. K., and L. H. Pedersen. 2009. “Market Liquidity and Funding Liquidity." Review of Financial Studies, forthcoming.

Burnside, C. 2007. "The Cross-Section of Foreign Currency Risk Premia and Consumption Growth Risk: A Comment." Working Paper no. 13129, NBER, Cambridge, MA.

Burnside, C., M. Eichenbaum, I. Kleshchelski, and S. Rebelo. 2006. "The Returns to Currency Speculation." Working paper, Duke University.

Burnside, C., M. S. Eichenbaum, and S. Rebelo. 2007. "Understanding the Forward Premium Puzzle: A Microstructure Approach." Working Paper no. 13278, NBER, Cambridge, MA.

Chen, J., H. Hong, and J. C. Stein. 2001. "Forecasting Crashes: Trading Volume, Past Returns and Conditional Skewness in Stock Prices." Journal of Financial Economics 61:345-81.

Collin-Dufresne, Pierre, R. S. Goldstein, and J. S. Martin. 2001. "The Determinants of Credit Spread Changes." Journal of Finance 56, no. 6:2177-2207.

Cutler, David M., J. M. Poterba, and L. H. Summers. 1989. "What Moves Stock Prices?" Working Paper no. 2538, NBER, Cambridge, MA.

Engel, C. 1996. "The Forward Discount Anomaly and the Risk Premium: A Survey of Recent Evidence." Journal of Empirical Finance 3:123-92.

Fair, R. C. 2002. "Events That Shook the Market." Journal of Business 75:713-32.

Fama, E. F. 1984. "Forward and Spot Exchange Rates." Journal of Monetary Economics 14:319-38.

Farhi, E., and X. Gabaix. 2008. "Rare Disasters and Exchange Rates." Working paper, Harvard University.

Froot, K. A. 2001. "The Market for Catastrophe Risk: A Clinical Examination." Journal of Financial Economics 60, nos. 2-3:529-71.

Froot, K. A., and P. O'Connell. 1999. "The Pricing of US Catastrophe Reinsurance." In The Financing of Catastrophe Risk, ed. K. A. Froot, 195-232. Chicago: University of Chicago Press. 
Froot, K. A., and R. H. Thaler. 1990. "Anomalies: Foreign Exchange." Journal of Economic Perspectives 4, no. 3:179-92.

Gagnon, J. E., and A. P. Chaboud. 2007. "What Can the Data Tell Us about Carry Trades in Japanese Yen?" International Finance Discussion Paper no. 899, Board of Governors of the Federal Reserve System, Washington, DC.

Galati, G., A. Heath, and P. McGuire. 2007. "Evidence of Carry Trade Activity." BIS Quarterly Review (September): 27-41.

Garman, M. B., and S. W. Kohlhagen. 1983. "Foreign Currency Option Values." Journal of International Money and Finance 2, no. 3:231-37.

Grossman, S. J. 1995. "Dynamic Asset Allocation and the Informational Efficiency of Markets." Journal of Finance 50, no. 3:773-87.

Jurek, J. 2007. “Crash-Neutral Currency Carry Trades." Working paper, Princeton University.

Jylhä, P., J.-P. Lyytinen, and M. Suominen. 2008. "Arbitrage Capital and Currency Carry Trade Returns." Working paper, Helsinki School of Economics.

Kilian, L. 1998. "Small-Sample Confidence Intervals for Impulse Response Functions." Review of Economics and Statistics 80, no. 2:218-30.

Klitgaard, T., and L. Weir. 2004. "Exchange Rate Changes and Net Positions of Speculators in the Futures Market." Federal Reserve Bank of New York Economic Policy Review 10, no. 1:17-28.

Lewis, K. 1995. "Puzzles in International Financial Markets." In Handbook of International Economics, vol. 3, ed. G. M. Grossman and K. Rogoff, chap. 37. Amsterdam: North-Holland.

Lustig, H., and A. Verdelhan. 2007. "The Cross-Section of Foreign Currency Risk Premia and US Consumption Growth Risk." American Economic Review 97, no. 1:89-117.

Meese, R. A., and K. Rogoff. 1983. "Empirical Exchange Rate Models of the Seventies: Do They Fit Out of Sample?" Journal of International Economics 14:3-24.

Mitchell, M., L. H. Pedersen, and T. Pulvino. 2007. "Slow Moving Capital." American Economic Review Papers and Proceedings 97, no. 2:215-20.

Pan, J., and K. Singleton. 2008. "Default and Recovery Implicit in the Term Structure of Sovereign CDS Spreads." Journal of Finance 63:2345-84.

Plantin, G., and H. S. Shin. 2007. "Carry Trades and Speculative Dynamics." Working paper, Princeton University.

Ranaldo, A., and P. Söderlind. 2007. "Safe Haven Currencies." Economics Discussion Paper no. 2007-22, University of St. Gallen. 
